\title{
O papel do rececionista na experiência turística em três cidades portuguesas Património Mundial
}

\author{
António José Pinheiro* \\ Instituto Universitário da Maia (Portugal) \\ Norberto Santos** \\ Universidade de Coimbra (Portugal)
}

\begin{abstract}
Resumo: Os estabelecimentos de alojamento turístico têm uma função estruturante na exploração do destino por parte dos visitantes. Os seus rececionistas assumem um papel relevante, pois enquanto componente humana do serviço têm, também, grande responsabilidade na divulgação das atividades de animação existentes no destino. Isto sucede com as atividades criadas para o turista, como com as existentes para a população autóctone, funcionando, pois, os rececionistas como hub de acesso à experiência e aos processos criativos locais. Apresentam, então, capacidade de influenciar as opções tomadas pelos hóspedes em matéria de visitação de locais, participação em eventos e experienciação de atividades de animação. Este estudo centra-se em três centros históricos portugueses, classificados como Património Mundial: Coimbra, Évora e Porto. As informações, recolhidas mediante inquéritos próprios e tratadas estatisticamente, permitiram avaliar as relações entre oferta e procura turística, intermediadas pelos rececionistas, comprovando que as suas sugestões influenciam, efetivamente, as decisões dos hóspedes no destino.
\end{abstract}

Palavras-chave: Rececionista; Hospitalidade; Alojamento turístico; Animação turística; Experiência; Turismo urbano; Património Mundial.

The role of the receptionist in the tourist experience in three Portuguese World Heritage cities

Abstract: Tourist accommodation establishments have a structuring function in the exploration of the destination by visitors. Its receptionists assume an important role, because as a human component of the service, they also have great responsibility in disseminating the animation activities existing in the destination. This happens with the activities created for the tourist, as with the existing ones for the native population. So, the receptionist operates as a hub for access to local experience and creative processes and, also, can influence the choices made by guests in visiting places, participating in events and experiencing entertainment activities. This study focuses on three Portuguese historic centres, classified as World Heritage: Coimbra, Évora and Porto. The information, collected through own inquiries and treated statistically, allowed to evaluate the relationship between tourism supply and demand, intermediated by the receptionists, proving that their suggestions effectively influence the decisions of the guests at the destination.

Keywords: Receptionist; Hospitality; Tourist accommodation; Tourist animation; Experience; Urban tourism; World Heritage.

\footnotetext{
* Instituto Universitário da Maia (Portugal); E-mail: ajpinheiro@ismai.pt

** Universidade de Coimbra (Portugal); E-mail: E-mail: norgeo@fl.uc.pt
} 


\section{Introdução}

Os estabelecimentos de alojamento turístico podem ter uma importância significativa no processo de preparação da viagem. Em contexto urbano, a seleção de um alojamento resulta da ponderação de aspetos como a localização relativa aos atrativos turísticos, a sua acessibilidade física (Shoval, McKercher, $\mathrm{Ng}$, \& Birenboim, 2011), o acesso a informação qualificada, o preço praticado e/ou a qualidade percebida pelo turista. A este nível, a opção tomada pelo turista influenciará a sua experiência na cidade, mas a influência dos serviços do alojamento turístico não se esgota nesta matéria. Na verdade, a experiência nas instalações do alojamento resultará na avaliação de satisfação que o turista efetuará relativamente a este serviço, porém a externalização de informação oferecida terá consequências na sua perceção global de satisfação face ao destino turístico urbano em que se insere o estabelecimento. Adicionalmente, os estabelecimentos de alojamento turístico, com as suas ações de prestação de informações e comercialização de experiências de animação podem ter a capacidade de influenciar as atividades que os seus hóspedes efetuam na cidade que visitam. Neste sentido, os alojamentos providenciam informação tanto em suportes físicos como digitais, seja nos seus canais à distância (sítio de Internet próprio, redes sociais e páginas de intermediários turísticos) ou no local. Claro que a origem dessa informação, ao nível da decisão de as selecionar, disponibilizar e controlar é, sobretudo, da responsabilidade dos gestores dos alojamentos (Puertas, 2007). Contudo, cabe aos recursos humanos de contacto direto com os hóspedes, nomeadamente os rececionistas que efetuam o acolhimento e auxílio durante a estada, a transmissão dessa informação, seja seguindo com rigor as instruções fornecidas pelos seus gestores, seja usando um maior grau de autonomia na prestação desses elementos, partilhando as suas próprias experiências.

O processo de interação entre hóspedes e rececionistas é um período de troca de informações e de estabelecimento de uma relação que tem o potencial de alterar ou balizar as perceções que o hóspede terá do destino turístico e ainda de o levar a realizar determinadas atividades na cidade. Considera-se que a atual experiência turística urbana se encontra facilitada pela profusão de informações disponibilizadas através de meios digitais que aumentam o conhecimento do turista, tanto no período de planeamento pré-viagem como durante a permanência no destino. Esta constatação pode levar a crer que a interação clássica com o rececionista enquanto fonte de informações turísticas e experiências sobre o local já não é tão necessária para a fruição do mesmo. Contudo, se os meios tecnológicos fornecem hoje uma excelente alternativa será que o recurso ao rececionista como fonte de informação sobre o destino decaiu e assume hoje um papel meramente acessório? Para responder a essa questão considerou-se relevante construir uma investigação que avaliasse, em primeiro lugar, o papel do rececionista enquanto fonte de informações primárias, junto dos hóspedes. Seguidamente, procurou-se compreender se as ações e atividades realizadas pelos hóspedes durante a estada foram efetivamente influenciadas pela eventual disponibilização de informações por parte dos rececionistas.

\section{Marco teórico}

O alojamento de visitantes a cidades, numa perspetiva de serviço, pode ser posicionado historicamente na época do Império Romano. Cunha (2013) faz menção direta a este aspeto referindo o conceito de hospitalidade como nuclear para a definição histórica de alojamento, entendido como um dever e sentido de honra. Séculos mais tarde, a década de 30 do século XIX marca o aparecimento da hotelaria tradicional. Seguem-se décadas de aprofundamento e desenvolvimento de novos conceitos de alojamento turístico. Apesar de todas as transformações, o serviço básico a prestar por um estabelecimento de alojamento mantém-se na disponibilização de um quarto para uso particular e com um caráter temporário. Consoante a dimensão e características do estabelecimento, outros serviços são apresentados. Davidoff (1994) sistematiza um total de quatro serviços: o check-in, a receção, o atendimento e a orientação inicial dos hóspedes; a acomodação; as telecomunicações e o check-out. Outros elementos adicionais podem ser considerados como: os serviços de mensageiros, a restauração e serviço de bares e as atividades culturais e de lazer (Pina \& Ribeiro, 2007). Destes serviços, salienta-se aqueles que podem significar a conexão e experiências no ambiente turístico onde o alojamento está integrado. Estes serviços passam pelas informações prestadas aquando do check-in e do atendimento durante a estada, permitindo a informação just-in-time de realizações locais e a divulgação de atividades culturais e de lazer. Sobre este último aspeto, é incomum a realização de atividades de animação pelos próprios estabelecimentos de alojamento em contexto de cidade. Na realidade, é mais frequente os alojamentos procurarem forma de se relacionarem com atividades de animação que ocorrem no destino turístico onde estão inseridos. 
Aliás, autores como Cândido \& Vieira (2003) defendem que qualquer tipo de alojamento pode equacionar formas de implementar e se interligar com atividades de animação, com enfoque para os elementos da oferta cultural e da gastronomia. Este tipo de ação poderá ter um impacto importante como fator de diferenciação do estabelecimento face a outros concorrentes. Este aspeto é particularmente relevante num contexto de meio urbano, onde a animação turística representa um domínio de união e criação de sinergias entre alojamentos e os centros históricos (Almeida \& Araújo, 2012).

O serviço de alojamento turístico pode ser visto como um conjunto integrado de interações e relacionamentos entre gestores, funcionários e hóspedes (Chen, 2016). Na prática, as interações entre hóspedes e os alojamentos ocorrem, fundamentalmente, em dois momentos distintos: na preparação da viagem e durante a mesma. Quanto à preparação, esta ocorre num ambiente de crescente autonomização do hóspede com recurso à Internet (Romão, 2013), seja através de intermediários como as OTA's - Online Travel Agencies (R. Costa, 2012) ou através de canais dos próprios alojamentos como os sítios na Internet, redes sociais ou ouras plataformas móveis (Moita, 2017).

$\mathrm{Na}$ interação durante a estada, considera-se que o conceito fundamental é a satisfação do hóspede. Partindo da definição das leis de Davidoff (1994), a satisfação é igual à perceção menos a expectativa. A expectativa é o resultado de fatores da personalidade do hóspede, de experiências anteriores no consumo de serviços similares e das informações obtidas sobre o alojamento (R. Costa, 2012), sendo que estas assumem um caracter cada vez mais determinante através do uso de ferramentas online de inscrição de comentários e atribuição de pontuação por parte dos consumidores. Autores como Martinelli (2004) e Almeida \& Araújo (2012) referem que aspetos como o tratamento individualizado, a forma de atendimento, a assistência facultada e a consistência na prestação do serviço são dos principais aspetos que o hóspede espera encontrar num alojamento. Numa perspetiva similar, que interliga satisfação com a interação humana no turismo, Barnes, Mattsson, Sørensen, \& Jensen (2020) apontam cinco fatores-chave da interação com os clientes: personalização, flexibilidade, cocriação, emoções e conhecimento. Depreende-se, pois, que a prestação de informações sobre a cidade e atividades de animação se enquadra na oferta de um serviço de alojamento mais completo e que corresponda às expectativas dos hóspedes.

$\mathrm{O}$ facto de existir interação do hóspede com o alojamento tanto na preparação da viagem como durante a sua realização, faculta ao alojamento um papel, não obrigatório, mas muito relevante para situações win-win de disponibilização de acesso a informação sobre o destino turístico. Considerando a categorização preconizada por J. Costa, Rita \& Águas (2004) das fontes de informação do turista em quatro grupos - comunicação interpessoal, mass média, média interativos e comunicação mediada por computador - o alojamento turístico tem capacidade de estar presente em todas. Não obstante a forte ponderação das componentes de média interativas e da comunicação por computador, as necessidades de informação levam os turistas a querer saber, no alojamento onde fazem check-in, sobre experiências e práticas que nem sempre são de fácil acesso através da comunicação online ou mediada tecnologicamente. Como referem Pina \& Ribeiro (2007), é o caso da programação de teatro, música e dança, cinemas, a existência de centros comerciais, restaurantes ou locais para passeio na cidade. Essa comunicação interpessoal é ainda reforçada pela corrente disponibilização de mass média nas receções físicas dos alojamentos, como os livros de viagens, mapas turísticos ou brochuras, associadas ou não a parcerias protocoladas.

Estes aspetos convergem para a figura do rececionista do alojamento turístico, enquanto anfitrião e elemento fundamental da comunicação interpessoal que se verifica durante a estada num destino. A interação entre funcionários e hóspedes é considerada tão importante que autores como Teng \& Barrows (2009) a colocam no mesmo nível de preocupações do setor hoteleiro junto com a busca da maior produtividade e da eficiência de custos. Outro contributo é obtido através do estudo de Mody, Suess \& Lehto (2019) que conclui que o setor do alojamento turístico encontra reais vantagens em incrementar a dimensão humana da experiência do hóspede através de características de genuína hospitalidade num cenário mercantilista. A importância da dimensão humana também é acompanhada por Oh, Jeong, \& Baloglu (2013) na análise efetuada ao desejo de interação dos hóspedes nos serviços de alojamento turístico. A constatação da existência de necessidades ou motivações emocionais que encontram resposta na interação humana leva estes autores a recomendar a adoção de soluções tecnológicas em formatos híbridos onde os funcionários mantêm um papel importante na prestação do serviço de alojamento, ao nível dos momentos de contacto com os hóspedes.

Repare-se que, na prática, o rececionista é a primeira pessoa do alojamento com quem o hóspede contacta e, muitas vezes, a única (R. Costa, 2012). Para além do papel de grande promotor do alojamento, cabe-lhe a interação com os clientes, a compreensão das suas motivações e a procura da sua satisfação (King, 1995). Concomitantemente, tem também a função de "fornecer aos hóspedes o maior número 
possível de informações sobre o hotel e sobre a cidade" (Marques, 2007, p. 312). Portanto, o rececionista desempenha um papel de difusor de informações sobre o destino turístico. Este papel é ainda acrescido de uma vertente comercial, pois alguns alojamentos, quando integrados em protocolos, comercializam bilhetes e entradas para variadas atividades de animação e eventos que ocorrem no destino turístico, sendo o rececionista o elemento operacional deste processo.

Reforçando esta perspetiva, Puertas (2007) considera mesmo o rececionista como um mediador da animação turística, ou seja o indivíduo que executa a ação de conexão direta entre um lugar, uma cultura, uma comunidade e os hóspedes. Para tal, este autor estabelece que o rececionista deve desenvolver competências ao nível do relacionamento com outros serviços, seja do estabelecimento onde está empregado, seja de outros serviços externos. Trata-se, pois, de informar e assessorar o hóspede sobre locais a visitar e experiências a realizar, relacionar-se com o meio, com orientações para as entidades e a comunidade do destino, e realizar atividades de descoberta de recursos para que possa informar o hóspede com uma visão mais aprofundada e experienciada.

A forma como os rececionistas estão preparados para desempenhar as suas funções, depende do facto de possuírem formação adequada (Marin citado por R. Costa, 2012), da sensibilização para uma perceção dos hóspedes respeitadora da diversidade e diferenças culturais (Moufakkir \& Alnajem, 2017), mas também de uma normalização de funções e conhecimentos que são traduzidos em fichas de descrição de funções e manuais de procedimentos que são desenvolvidos e instituídos pelos gestores dos alojamentos turísticos. Autores como Marques (2007) e R. Costa (2012) referem a conveniência e importância destes instrumentos desde que não limitem a capacidade do rececionista de responder a realidades do momento e específicas do cliente.

\section{Metodologia e estudo de caso}

A resposta à questão sobre a capacidade de influência dos rececionistas na experiência turística dos hóspedes de alojamentos implica conhecer as atividades e opções tomadas pelos hóspedes, mas também, as perceções dos rececionistas e as ações que realizam neste âmbito. Portanto, tornou-se necessário equacionar um modelo de investigação que ponderasse a recolha de informações tanto ao nível da procura como da oferta turística.

Para atingir o objetivo de compreender o papel do rececionista na experiência turística, procurou-se dar resposta a quatro questões fundamentais:

- Qual a perceção dos rececionistas face à importância da divulgação de atividades de animação para o estabelecimento de alojamento?

- Existe procura ativa dos hóspedes, junto dos rececionistas, de informações sobre atividades de animação?

- A interação com os rececionistas contribuiu positivamente para a satisfação dos hóspedes?

- A comunicação dos rececionistas, no sentido da sugestão ou comercialização, influenciou as atividades de animação realizadas pelos hóspedes?

Em termos práticos, tomou-se a decisão de efetuar uma análise no contexto do turismo urbano, tendo-se selecionado três centros históricos de Portugal: Coimbra, Évora e Porto. São três destinos turísticos de relevo do turismo urbano e cultural português, tendo em comum o facto de beneficiaram da notoriedade concedida pela classificação de Património Mundial. Os seus atributos enquanto destinos turísticos encontram-se em escalas diferentes que podem ser aferidas pelo número de hóspedes anual, que destacam o Porto como cidade com uma procura maior - 1.876.720 hóspedes no ano de 2018 (Instituto Nacional de Estatístca I.P., 2018c) em relação aos 430.076 hóspedes de Coimbra (Instituto Nacional de Estatístca I.P., 2018b) e 383.765 de Évora (Instituto Nacional de Estatístca I.P., 2018a), no mesmo período. Os aspetos em comum e os aspetos diferenciais tornam estas três cidades um conjunto relevante tanto para uma análise conjunta como para uma análise comparada.

Em termos operacionais limitou-se a pesquisa a todos os estabelecimentos que prestam serviços de alojamento turístico dentro das áreas classificadas como Património Mundial (no caso de Évora e Porto apenas a área classificada em si e, por motivos de obtenção de uma amostra mais numerosa, no caso de Coimbra englobou-se também a área de proteção da área classificada). Optou-se pela realização de inquéritos por questionário junto dos hóspedes e rececionistas. 
Os questionários foram disponibilizados a todos os rececionistas e a todos os hóspedes alojados, de maio a agosto do ano de 2017, nos estabelecimentos de alojamento com serviço de receção humanizada a hóspedes.

Relativamente às amostras concretizadas, para os rececionistas, foram enviados inquéritos para todos os estabelecimentos de alojamento legalizados nas áreas territoriais atrás referidas, tendo-se obtido a autorização de 67 gestores de estabelecimentos (Coimbra $=22$, Évora $=18$ e Porto $=27)$ para inquirir os seus rececionistas. Nesse momento foi questionado o número total de rececionistas em cada estabelecimento e a partir daí efetuou-se uma extrapolação para estimar o universo de rececionistas nos centros históricos em estudo, aferindo-se, assim, as taxas de amostragem obtidas (tabela 1). No total, foram inquiridos 131 rececionistas, o que representa uma taxa de amostragem de $41,1 \%$.

Tabela 1: Universos e amostras de rececionistas nos centros históricos

\begin{tabular}{|l|c|c|c|c|}
\hline $\begin{array}{c}\text { Centro } \\
\text { Histórico }\end{array}$ & $\begin{array}{c}\text { Amostra de } \\
\text { rececionistas } \\
\text { obtida (n) }\end{array}$ & $\begin{array}{c}\text { Média de } \\
\text { rececionistas por } \\
\text { estabelecimento }\end{array}$ & $\begin{array}{c}\text { Extrapolação } \\
\text { estimativa do total de } \\
\text { rececionistas }\end{array}$ & $\begin{array}{c}\text { Taxa de } \\
\text { amostragem } \\
\text { face ao total } \\
\text { estimado de } \\
\text { rececionistas (\%) }\end{array}$ \\
\hline Coimbra & 39 & 2,5 & 110 & $35,5 \%$ \\
\hline Évora & 26 & 2,4 & 70 & $37,1 \%$ \\
\hline Porto & 66 & 2,9 & 139 & $47,5 \%$ \\
\hline Total & $\mathbf{1 3 1}$ & - & $\mathbf{3 1 9}$ & $\mathbf{4 1 , 1 \%}$ \\
\hline
\end{tabular}

Fonte: Elaboração própria.

No que concerne aos hóspedes, considerou-se como população em estudo os hóspedes nos alojamentos localizados nos 3 centros históricos, que de acordo com os dados atrás referidos, no ano de 2017, totalizou 2.690.561. Atente-se que este número considera a totalidade dos 3 concelhos em estudo e não especificamente dos seus centros históricos, pelo que o número de hóspedes nesses 3 territórios será consideravelmente inferior. No entanto, para efeitos de representatividade, mesmo considerando uma população perto de 2,7 milhões, esta encontra-se assegurada por uma amostra mínima de 384 efetivos, atendendo a um erro aceite de 0,1 em desvios-padrões e para um nível de confiança de 95\%, como sustenta uma relação de dimensão de população com a amostra apresentada por Abreu (2006, p. 103). Se for tido cada centro histórico individualmente, a representatividade encontra-se assegurada para Coimbra e Porto, sendo que em Évora terá de se aceitar um erro de 0,2 em desvios-padrões para o mesmo nível de confiança de 95\% (tabela 2). Portanto, contabilizaram-se 1073 inquéritos válidos de hóspedes.

Tabela 2: Quantificação das amostras de hóspedes

\begin{tabular}{|l|c|}
\hline \multicolumn{1}{|c|}{ Centro histórico } & Amostra de hóspedes (n) \\
\hline Coimbra & 402 \\
\hline Évora & 256 \\
\hline Porto & 415 \\
\hline$\sum$ & 1073 \\
\hline
\end{tabular}

Fonte: Elaboração própria.

De referir que os dados obtidos foram sujeitos a análise estatística descritiva com recurso ao software de análise SPSS. 


\section{Resultados}

A análise de resultados efetuou-se em consonância com as quatro questões fundamentais atrás identificadas, considerando especificamente cada uma das três cidades e a soma dos seus resultados.

\subsection{Perceção dos rececionistas face à importância da divulgação de atividades de animação para o estabelecimento de alojamento}

Quando colocados perante a afirmação "É importante para o estabelecimento onde trabalho divulgar atividades de animação turística que ocorrem no centro histórico" (tabela 3) a clara maioria dos rececionistas concorda com ela. Adicionadas as respostas "concordo" e "concordo totalmente", verifica.se que quase $91 \%$ de todos os rececionistas reconhecem a importância da divulgação de atividades de animação para os estabelecimentos de alojamento turístico. Este comportamento repercute-se nas amostras para cada cidade de forma muito próxima. No polo oposto, da discordância face a esta situação, constata-se um reduzido grupo que representa $3 \%$ da amostra total de rececionistas.

Tabela 3: Perceção sobre a importância da animação pelos rececionistas

\begin{tabular}{|l|c|c|c|c|}
\hline \multicolumn{1}{|c|}{ Item* } & Coimbra & Évora & Porto & TOTAL \\
\hline $\begin{array}{l}\text { Concordo } \\
\text { totalmente }\end{array}$ & 64,1 & \% de casos & \% de casos & \% de casos \\
\hline Concordo & 30,8 & 38,5 & 50,0 & $\mathbf{5 5 , 0}$ \\
\hline Indiferente & 5,1 & 7,7 & 37,9 & $\mathbf{3 5 , 9}$ \\
\hline Discordo & 0,0 & 0,0 & 1,5 & $\mathbf{6 , 1}$ \\
\hline $\begin{array}{l}\text { Discordo } \\
\text { totalmente }\end{array}$ & 0,0 & 0,0 & 4,6 & $\mathbf{0 , 8}$ \\
\hline \multicolumn{2}{|c|}{ Total } & $\mathbf{n = 3 9}$ & $\mathbf{n = 2 6}$ & $\mathbf{n}=\mathbf{6 6}$ \\
\hline $\begin{array}{l}\text { Item*: É importante para o estabelecimento onde trabalha divulgar atividades de animação turística que } \\
\text { ocorrem no centro histórico. }\end{array}$
\end{tabular}

Fonte: Elaboração própria baseada nos inquéritos por questionário realizados aos rececionistas

Considerando os motivos pelos quais os rececionistas consideram importante a divulgação de atividades de animação pelos estabelecimentos de alojamento turístico, procurou-se indagar quais os fundamentos para a sua resposta afirmativa (tabela 4). Neste âmbito, encontraram-se dois argumentos que reúnem um consenso alargado, com mais de $83 \%$ dos inquiridos: i) o acréscimo de valor ao serviço de alojamento, ao constituir-se como mais um serviço prestado no local, e ii) o contributo que a divulgação de atividades pode ter para o desenvolvimento da cidade. De forma minoritária, mas mesmo assim, indicados por números consideráveis de rececionistas surgem iii) o contributo para o aumento da estada dos hóspedes no alojamento (45,3\%) e iv) o facto de serem uma fonte de receitas adicional à atividade de alojamento $(31,9 \%)$. $\mathrm{Na}$ análise comparativa verificam-se duas inversões relativamente à ordem atrás referida. Como argumento mais importante, Évora considera o contributo para o desenvolvimento da cidade por troca com o acrescento de valor ao serviço. O Porto valoriza o argumento de ser uma fonte de receitas adicional face ao aumento da estada no alojamento. 
Tabela 4: Argumentos para considerar importante a animação pelos rececionistas

\begin{tabular}{|l|c|c|c|c|}
\hline \multicolumn{1}{|c|}{ Argumentos * } & Coimbra & Évora & Porto & TOTAL \\
\hline $\begin{array}{l}\text { Acrescenta valor ao serviço de } \\
\text { alojamento }\end{array}$ & 91,2 & 75,0 & 86,2 & $\mathbf{8 5 , 7}$ \\
\hline $\begin{array}{l}\text { Contribui para o desenvolvimento } \\
\text { da cidade }\end{array}$ & 86,5 & 95,8 & 75,9 & $\mathbf{8 3 , 2}$ \\
\hline Aumento da estada no alojamento & 54,1 & 62,5 & 32,8 & $\mathbf{4 5 , 3}$ \\
\hline Fonte de receitas adicional & 21,6 & 16,7 & 44,8 & $\mathbf{3 1 , 9}$ \\
\hline Outros & 5,4 & 12,5 & 3,4 & $\mathbf{5 , 9}$ \\
\hline Total & $\mathrm{n}=37$ & $\mathrm{n}=24$ & $\mathrm{n}=58$ & $\mathbf{n = 1 1 9}$ \\
\hline * Esta questão é de resposta múltipla & & & \\
\hline
\end{tabular}

Fonte: Elaboração própria baseada nos inquéritos por questionário realizados aos rececionistas

Tendo-se verificado de forma muito evidente a perceção positiva dos rececionistas face à divulgação das atividades de animação e os argumentos que a sustentam, tornou-se relevante perceber se essa perceção era acompanhada com ações efetivas, levadas a cabo pelos rececionistas, quanto à divulgação das atividades. Para tal, foi questionada a frequência com que sugerem aos hóspedes locais a visitar, realização de eventos e participação em experiências. As respostas podem ser analisadas isolando os rececionistas que, na tabela 3 , demonstraram concordância com a afirmação sobre a importância da divulgação das atividades de animação. Assim sendo, na tabela 5, constata-se que 93,3\% dos rececionistas que têm uma perceção de concordância sugerem locais a visitar com uma frequência elevada e que $65,6 \%$ também o fazem relativamente a eventos. No que concerne a experiências (passeios organizados ou serviços variados de empresas de animação turística) apenas uma minoria (37,3\%) o faz com elevada frequência. Atente-se, ainda, que a maioria dos rececionistas que não vê importância na divulgação de animação divulga com uma frequência baixa eventos e experiências, mas, inversamente, $83,3 \%$ sugerem locais a visitar aos hóspedes.

\section{Tabela 5: Perceção da importância de divulgação das atividades de animação vs sugestões (totais das 3 cidades)}

\begin{tabular}{|l|c|c|c|c|c|c|c|}
\hline \multirow{2}{*}{$\begin{array}{l}\text { Importância da } \\
\text { divulgação de } \\
\text { atividades }\end{array}$} & & \multicolumn{2}{|c|}{$\begin{array}{c}\text { Sugestão de locais a } \\
\text { visitar }\end{array}$} & \multicolumn{2}{c|}{ Sugestão de eventos } & \multicolumn{2}{c|}{$\begin{array}{c}\text { Sugestão de } \\
\text { experiências }\end{array}$} \\
\cline { 2 - 8 } & & $\begin{array}{c}\text { Freq. } \\
\text { elevada }\end{array}$ & $\begin{array}{c}\text { Freq. } \\
\text { baixa ou } \\
\text { nula }\end{array}$ & $\begin{array}{c}\text { Freq. } \\
\text { elevada }\end{array}$ & $\begin{array}{c}\text { Freq. } \\
\text { baixa ou } \\
\text { nula }\end{array}$ & $\begin{array}{c}\text { Freq. } \\
\text { elevada }\end{array}$ & $\begin{array}{c}\text { Freq. } \\
\text { baixa ou } \\
\text { nula }\end{array}$ \\
\hline Concordância & $\mathbf{f}$ & 111 & 8 & 78 & 41 & 44 & 74 \\
\cline { 2 - 8 } & $\mathbf{\%}$ & 93,3 & 6,7 & 65,6 & 34,4 & 37,3 & 62,7 \\
\hline $\begin{array}{l}\text { Discordância ou } \\
\text { Neutralidade }\end{array}$ & $\mathbf{f}$ & 10 & 2 & 5 & 7 & 2 & 10 \\
\cline { 2 - 8 } & $\mathbf{9}$ & 83,3 & 16,7 & 41,7 & 58,3 & 16,7 & 83,3 \\
\hline
\end{tabular}

Fonte: Elaboração própria baseada nos inquéritos por questionário realizados aos rececionistas

\subsection{Existência de procura ativa dos hóspedes, junto dos rececionistas, de informações sobre atividades de animação}

Não obstante o acesso a informação que os turistas dispõem por meios telemáticos, a procura de informações personalizadas nas receções dos alojamentos turísticos é uma prática enraizada e evidenciada 
neste estudo de caso. Em termos agregados (tabela 6), 83,5\% dos hóspedes efetuou pedidos de informação na receção, sendo este número um pouco mais elevado nos hóspedes de Coimbra e Évora (na ordem dos $86 \%)$ e ligeiramente menor no Porto (78,8\%).

Tabela 6: Realização de pedidos de informações na receção

\begin{tabular}{|l|c|c|c|c|c|c|c|c|}
\hline & \multicolumn{2}{|c|}{ Coimbra } & \multicolumn{2}{c|}{ Évora } & \multicolumn{2}{c|}{ Porto } & \multicolumn{2}{c|}{ TOTAL } \\
\hline \multicolumn{1}{|c|}{ Realização } & $\mathbf{f}$ & $\mathbf{\%}$ & $\mathbf{f}$ & $\mathbf{\%}$ & $\mathbf{f}$ & $\mathbf{\%}$ & $\mathbf{f}$ & $\mathbf{\%}$ \\
\hline Sim & 348 & 86,6 & 221 & 86,3 & 327 & 78,8 & 896 & 83,5 \\
\hline Não & 54 & 13,4 & 35 & 13,7 & 88 & 21,2 & 177 & 16,5 \\
\hline Total & $\mathbf{4 0 2}$ & $\mathbf{1 0 0}$ & $\mathbf{2 5 6}$ & $\mathbf{1 0 0}$ & $\mathbf{4 1 5}$ & $\mathbf{1 0 0}$ & $\mathbf{1 0 7 3}$ & $\mathbf{1 0 0}$ \\
\hline
\end{tabular}

Fonte: Elaboração própria baseada nos inquéritos por questionário realizados aos hóspedes

Especificando o tipo de informações solicitadas na receção, constata-se que tanto as indicações sobre restaurantes e sobre atrativos a visitar reúnem, de forma destacada das demais, a maioria das perguntas efetuadas pelos hóspedes (tabela 7). Para o agregado das três cidades, cada um destes dois tipos de solicitação de informações foi efetuada por 58\% dos hóspedes inquiridos. No Porto, esse equilíbrio mantém-se com valores na ordem dos $51 \%$, mas nas outras duas cidades existem destaques diferentes. Assim, em Coimbra, regista-se que as informações mais pedidas se referem aos atrativos a visitar $(68,4 \%)$ seguindo-se os pedidos sobre restaurantes (59.5\%). Em Évora ocorre o inverso, com os pedidos de informações sobre restaurantes a ocupar o primeiro lugar (68\%) seguindo-se as solicitações sobre atrativos a visitar (51,6\%). Com menor expressão surgem pedidos de informações sobre eventos, atividades de animação e espaços de animação noturna, com valores agregados que oscilam entre $18 \%$ e $26 \%$.

Tabela 7: Informações pedidas na receção

\begin{tabular}{|l|c|c|c|c|}
\hline \multicolumn{1}{|c|}{ Informações * } & Coimbra & Évora & Porto & TOTAL \\
\hline Restaurantes & \% de casos & \% de casos & \% de casos & \% de casos \\
\hline Atrativos a visitar na cidade & 59,5 & 68,0 & 51,1 & 58,2 \\
\hline Eventos que estão a decorrer na cidade & 68,4 & 51,6 & 51,8 & 58,0 \\
\hline Atividades de animação para fazer na cidade & 28,4 & 37,9 & 16,1 & 25,9 \\
\hline Locais de animação noturna & 21,9 & 30,5 & 16,9 & 22,0 \\
\hline Outras & 25,6 & 12,9 & 14,0 & 18,0 \\
\hline Total & 10,9 & 0,8 & 12,8 & 9,2 \\
\hline * Esta questão é de resposta múltipla & $\mathbf{n = 4 0 2}$ & $\mathbf{n = 2 5 6}$ & $\mathbf{n = 4 1 5}$ & $\mathbf{n = 1 0 7 3}$ \\
\hline
\end{tabular}

Fonte: Elaboração própria baseada nos inquéritos por questionário realizados aos hóspedes

\subsection{Contributo positivo da interação com os rececionistas para a satisfação dos hóspedes}

Tendo-se constatado que existe uma interação real entre hóspedes e rececionistas, pois os primeiros, numa larga maioria, procuram ativamente informações sobre aspetos da cidade e os segundos afirmam prestar sugestões com elevada frequência, importa avaliar se essa interação é satisfatória do ponto de vista da procura turística. Procurou-se saber qual a visão dos hóspedes sobre três situações muito concretas da interação que tiveram com os rececionistas:

- Cumprimento das expectativas dos hóspedes face às perguntadas colocadas aos rececionistas;

- Interesse das sugestões efetuadas pelos rececionistas;

- Conhecimentos sobre a cidade, demonstrados pelos rececionistas. 
Os resultados obtidos foram tratados através de medidas de estatística descritiva de tendência central (média, moda, mediana e desvio-padrão) e traduzem-se numa concordância generalizada aos itens colocados (tabela 8). Seja numa análise comparativa ou numa análise agregada, os valores médios estão muito próximos, oscilando entre 4,0 e 4,3. As medianas encontram-se todas no 4, ou seja, a resposta "concordo". Os valores da moda assumem sempre a resposta "concordo", exceto nos itens 2 e 3, na cidade do Porto, onde a moda - isto é a resposta maioritária - se encontra na opção "concordo totalmente".

Para se validar estatisticamente estes resultados, efetuou-se uma análise de consistência interna. Optou-se por calcular o Alpha de Cronbach, que "é uma das medidas mais usadas para verificação da consistência interna de um grupo de variáveis (itens), podendo definir-se como a correlação que se espera obter entre a escala usada e outras escalas hipotéticas do mesmo universo, com igual número de itens, que meçam a mesma característica. Varia entre 0 e 1" (Pestana \& Gageiro, 2014, p. 531). Assim sendo, para os dados agregados das 3 cidades, obteve-se um alpha de 0,89. Por cidade, os resultados foram de 0,93 (Porto), 0,88 (Coimbra) e 0,75 (Évora). Considerando que um alpha entre 0,8 e 0,9 se refere a uma consistência interna boa (Pestana \& Gageiro, 2014, p. 531), apenas a amostra isolada de Évora fica um pouco aquém, mas mesmo assim é tida como razoável. Também se efetuou uma análise complementar excluindo os itens um a um, o que resultou que em nenhum caso se assistiu a uma melhoria do alpha, por isso todos os itens se mostram consistentes com a variável em medição. Portanto, comprova-se uma generalizada satisfação dos hóspedes com a interação tida com os rececionistas.

Tabela 8: Perceções sobre a interação com os rececionistas

\begin{tabular}{|l|c|c|c|c|c|c|c|c|c|c|c|c|}
\hline & \multicolumn{3}{|c|}{ Coimbra } & \multicolumn{3}{c|}{ Évora } & \multicolumn{3}{c|}{ Porto } & \multicolumn{3}{c|}{ TOTAL } \\
\hline \multicolumn{1}{|c}{ Itens* } & $\mathbf{1}$ & $\mathbf{2}$ & $\mathbf{3}$ & $\mathbf{1}$ & $\mathbf{2}$ & $\mathbf{3}$ & $\mathbf{1}$ & $\mathbf{2}$ & $\mathbf{3}$ & $\mathbf{1}$ & $\mathbf{2}$ & $\mathbf{3}$ \\
\hline n I válidos & 374 & 370 & 363 & 249 & 247 & 245 & 365 & 370 & 364 & 988 & 987 & 972 \\
\hline NS/NR & 28 & 32 & 39 & 7 & 9 & 11 & 50 & 45 & 51 & 85 & 86 & 101 \\
\hline Média & 4,2 & 4,0 & 4,2 & 4,3 & 4,0 & 4,2 & 4,2 & 4,1 & 4,2 & 4,2 & 4,0 & 4,2 \\
\hline Mediana & 4 & 4 & 4 & 4 & 4 & 4 & 4 & 4 & 4 & 4 & 4 & 4 \\
\hline Moda & 4 & 4 & 4 & 4 & 4 & 4 & 4 & 5 & 5 & 4 & 4 & 4 \\
\hline Desvio-padrão & 0,8 & 0,9 & 0,8 & 0,6 & 0,8 & 0,7 & 0,9 & 1,1 & 1,0 & 0,8 & 0,9 & 0,9 \\
\hline
\end{tabular}

Itens*:

1. As informações prestadas na receção corresponderam ao que eu pretendia saber.

2. A receção efetuou sugestões que contribuíram para melhorar a minha experiência na cidade.

3. O rececionista a quem mais questões efetuei demonstrou que é conhecedor da cidade.

Escala: (1) Discordo totalmente | (2) Discordo | (3) Indiferente | (4) Concordo | (5) Concordo totalmente | (NS/NR) Não sabe / Não respondeu

Fonte: Elaboração própria baseada nos inquéritos por questionário realizados aos hóspedes

\subsection{Influência da comunicação dos rececionistas, no sentido da sugestão ou comercialização, nas atividades de animação realizadas pelos hóspedes}

Conforme se verificou nos dados da tabela 5, uma clara maioria dos rececionistas efetua sugestões de locais e eventos a visitar e, embora de forma minoritária, mas mesmo assim expressiva, experiências de animação a usufruir. Esta constatação leva à interrogação sobre se estas sugestões são efetivamente tidas em conta pelos hóspedes durante a sua permanência na cidade. Para procurar responder a esta questão, operacionalizaram-se duas estratégias: uma referente aos atrativos e eventos visitados e outra em relação às atividades de animação adquiridas.

Quanto aos atrativos e eventos, efetuou-se um rácio que relaciona os locais visitados pelos hóspedes com as sugestões efetuadas pelos rececionistas. Na prática, pretende-se saber se as sugestões foram seguidas. Para esta tarefa, foi questionado previamente aos hóspedes quais os atrativos que planearam visitar antes da realização da viagem para que estes fossem excluídos desta análise. Por exemplo, um atrativo que já fazia parte do plano de viagem do hóspede e que no alojamento foi também sugerido 
pelo rececionista e que acabou por ser efetivamente visitado pelos hóspede não é contabilizado neste rácio, pois não se conseguiria saber se a sugestão do rececionista foi um fator suficiente para influenciar a decisão da visita. Assim sendo, respeitando este critério, contabilizaram-se exclusivamente os atrativos que de forma simultânea combinam as variáveis de visita efetiva e de sugestão prévia pelo rececionista. Os resultados (tabela 9) apontam que 67,9\% das sugestões de visita a atrativos e eventos foram efetivamente seguidas pelos hóspedes, considerando um agregado das 3 cidades. Considerando a análise comparativa, verifica-se que Coimbra se encontra com um número alinhado face ao agregado (67\%), Évora apresenta um rácio ligeiramente superior $(72,8 \%)$ e o Porto um pouco inferior $(64,8 \%)$. Ainda em termos específicos por cidade, acrescenta-se que em cada uma das três cidades 10 atrativos atingem rácios superiores a 50\%, o que significa que pelo menos metade das sugestões foram seguidas pelos hóspedes, e que os 3 atrativos mais cotados se localizam nos próprios centros históricos ou nas suas proximidades mais imediatas, evidenciando o papel fulcral do rececionista na informação sobre as atrações e o território.

\section{Tabela 9: Rácio entre atrativos visitados e sugestão prévia pelos rececionistas ( 3 mais cotados por cidade e totais)}

\begin{tabular}{|l|c|c|c|}
\hline \multicolumn{1}{|c|}{ Atrativos e eventos } & \multicolumn{2}{c|}{ Situações } & \multirow{2}{*}{$\begin{array}{c}\text { Rácio } \\
\text { Experienciado / } \\
\text { Sugerido (\%) }\end{array}$} \\
\hline Coimbra & Experienciado & Sugerido & 67,0 \\
\hline > Universidade de Coimbra & 160 & 1225 & 93,0 \\
\hline > Sé Velha & 109 & 172 & 90,8 \\
\hline > Arco de Almedina & 83 & 120 & 86,5 \\
\hline Évora & 544 & 96 & 72,8 \\
\hline > Praça do Giraldo & 84 & 747 & 100 \\
\hline > Templo Romano & 84 & 84 & 97,7 \\
\hline > Catedral & 69 & 75 & 92,0 \\
\hline Porto & 511 & 789 & 64,8 \\
\hline > Ribeira & 58 & 58 & 100 \\
\hline > Estação de S. Bento & 70 & 75 & 93,3 \\
\hline > Caves do Vinho do Porto & 70 & 78 & 89,7 \\
\hline TOTAL & $\mathbf{1 8 7 6}$ & $\mathbf{2 7 6 1}$ & $\mathbf{6 7 , 9}$ \\
\hline
\end{tabular}

Fonte: Elaboração própria baseada nos inquéritos por questionário realizados aos hóspedes

Relativamente à estratégia, atrás anunciada, sobre as atividades de animação adquiridas, os hóspedes foram confrontados com duas questões: i) que tipos de atividades de animação lhes foram sugeridas no alojamento e ii) quais as que efetivamente adquiriu. Nesta matéria (tabela 10), observa-se que 4 atividades de animação se destacam no agregado de dados das três cidades, com valores entre 13,2\% e 16,7\% cada: i) passeio de barco (não referidos em Évora), ii) tour a pé com guia, iii) circuito de autocarro (não referido em Évora) e iv) bilhete para espetáculo de fado (não referido em Évora e Porto). Comparativamente existem especificidades que resultam de dinâmicas e escalas de animação urbanas próprias, o que resulta, por exemplo, no bilhete para espetáculos de fado como a atividade mais sugerida em Coimbra (35,3\%). No Porto o passeio de barco no Douro ocupa o primeiro lugar (28,2\% dos hóspedes). Esta mesma tabela, também apresenta a percentagem de hóspedes que efetivamente comprou os tipos de atividades de animação referidos. Se for efetuado o seu somatório e 
comparado proporcionalmente com as sugestões de atividades de animação, verifica-se uma proporção de 64 compras para cada 100 sugestões, considerando o agregado das 3 cidades.

\section{Tabela 10: Sugestão de atividades de animação pelos rececionistas e compra de atividades de animação pelos hóspedes}

\begin{tabular}{|c|c|c|c|c|c|c|c|c|}
\hline \multirow[b]{2}{*}{ Sugestões * } & \multicolumn{2}{|c|}{$\begin{array}{l}\text { Coimbra } \\
\% \text { de casos }\end{array}$} & \multicolumn{2}{|c|}{$\begin{array}{c}\text { Évora } \\
\text { \% de casos }\end{array}$} & \multicolumn{2}{|c|}{$\begin{array}{c}\text { Porto } \\
\text { \% de casos }\end{array}$} & \multicolumn{2}{|c|}{$\begin{array}{c}\text { TOTAL } \\
\% \text { de casos }\end{array}$} \\
\hline & Sug. & Com. & Sug. & Com. & Sug. & Com. & Sug. & Com. \\
\hline Passeio de barco & 15,4 & 7,0 & -- & -- & 28,2 & 21,9 & 16,7 & 13,7 \\
\hline Tour a pé com guia & 15,7 & 7,5 & 10,5 & 5,5 & 14,7 & 8,0 & 14,1 & 7,2 \\
\hline Circuito de autocarro na cidade & 19,9 & 9,5 & -- & -- & 16,1 & 13,8 & 13,7 & 8,9 \\
\hline Bilhete para espetáculo de fado & 35,3 & 20,2 & -- & -- & -- & -- & 13,2 & 7,5 \\
\hline Passeio de $t u k t u k$ & 11,2 & 5,0 & 3,1 & 3,1 & 5,8 & 2,4 & 7,2 & 3,5 \\
\hline Bilhete para espetáculo & -- & -- & 2,3 & 1,2 & 11,3 & 4,6 & 4,9 & 2,1 \\
\hline Provas de vinhos & -- & -- & 8,6 & 5,5 & -- & -- & 2,1 & 1,3 \\
\hline Tour de bicicleta & -- & -- & 2,3 & 1,2 & -- & -- & 0,6 & 0,3 \\
\hline Outras & 0,7 & 0,8 & 7,8 & 7,8 & 4,1 & 4,6 & 3,7 & 3,9 \\
\hline Total & \multicolumn{2}{|c|}{$n=402$} & \multicolumn{2}{|c|}{$n=256$} & \multicolumn{2}{|c|}{$n=415$} & \multicolumn{2}{|c|}{$n=1073$} \\
\hline
\end{tabular}

Fonte: Elaboração própria baseada nos inquéritos por questionário realizados aos hóspedes

Adicionalmente, o cruzamento das variáveis "sugestão" e "compra" permitiu elaborar tabelas de contingência que facultam a possibilidade de isolar os hóspedes que adquiriram entradas para atividades de animação e, dentro desse grupo, distinguir aqueles que compraram após a sugestão por parte dos rececionistas daqueles que adquiririam atividades sem qualquer sugestão recebida. Realizou-se a comprovação destes dados estatisticamente, mediante a realização de testes entre estas duas variáveis. O Teste do Qui-Quadrado é o mais indicado para analisar a associação entre duas variáveis qualitativas (Pestana \& Gageiro, 2014, p. 277), neste caso a sugestão e a compra da atividade. Os testes foram realizados individualmente para cada cidade e para cada tipo de atividade tendo-se verificado resultados em que $p \leq 0,05$ em todos, pelo que se conclui que existe uma associação significativa estatisticamente entre a sugestão e a compra.

Para uma melhor visualização deste fenómeno, elaborou-se um rácio que relacionada as compras de atividades efetuadas após sugestão pelo rececionista com o total das compras (tabela 11). Os resultados apontam todos no sentido de que a maioria das compras ocorreu associada com uma sugestão por parte do rececionista. No agregado das três cidades observa-se que $71,3 \%$ das compras tiveram uma sugestão associada e que em todos os tipos de atividades as compras com sugestão são maioritárias, superando sempre $63 \%$ e indo até valores cerca de $95 \%$. A realidade de cada cidade acompanha esta constatação, embora com intensidades diferentes. Évora regista, claramente, o maior volume de compras com sugestão, com um valor total de $88,7 \%$ face ao total de compras. Ao contrário, Coimbra apresenta o rácio mais baixo face às outras cidades, com $62,5 \%$ e, inclusive, apresenta as duas únicas atividades em que a maioria das compras foi efetuada sem a existência de sugestão prévia por parte do rececionista (passeio de tuk $t u k-45 \%$ e passeio de barco - 42,9\%). Estas constatações podem indiciar uma maior capacidade comercial por parte dos rececionistas de Évora e menor em Coimbra, na medida em que o Porto apresenta um rácio $(71,3 \%)$ alinhado com 
o total das três cidades. Todavia, esta menor influência dos rececionistas na aquisição de entradas ou bilhetes para atividades possa ter tido a ver com a qualidade dos produtos em referência no período de recolha de dados.

Tabela 11: Compras realizadas com sugestão prévia pelo rececionista

\begin{tabular}{|l|c|c|c|c|}
\hline & Coimbra & Évora & Porto & TOTAL \\
\hline Sugestões * & \% de casos & \% de casos & \% de casos & \% de casos \\
\hline Outras & 100 & 100 & 89,5 & 95,2 \\
\hline Bilhete para espetáculo & -- & 66,7 & 94,7 & 90,9 \\
\hline Provas de vinhos & -- & 85,7 & -- & 85,7 \\
\hline Bilhete para espetáculo de fado & 72,8 & -- & -- & 72,8 \\
\hline Circuito de autocarro na cidade & 65,8 & -- & 71,9 & 69,5 \\
\hline Tour de bicicleta & -- & 66,7 & -- & 66,7 \\
\hline Tour a pé com guia & 56,6 & 85,7 & 63,6 & 64,9 \\
\hline Passeio de barco & 42,9 & -- & 71,4 & 64,7 \\
\hline Passeio de tuk tuk & 45,0 & 87,5 & 80,0 & 63,1 \\
\hline Total & $\mathbf{6 2 , 5}$ & $\mathbf{8 8 , 7}$ & $\mathbf{7 4 , 2}$ & $\mathbf{7 1 , 3}$ \\
\hline * Esta questão é de resposta múltipla & & & \\
\hline
\end{tabular}

Fonte: Elaboração própria baseada nos inquéritos por questionário realizados aos hóspedes

\section{Conclusões}

O marco teórico considerado e analisado permitiu assumir alguns pressupostos com os quais se encarou o estudo. Em primeiro lugar a divulgação da oferta de animação turística, entendendo-se aqui a animação como um campo alargado de atividades que englobam as experiências adquiridas a empresas especializadas até às simples visitas a atrativos, por parte dos alojamentos são entendidas como forma de aumentar e diferenciar os serviços prestados por estes estabelecimentos. Nesta ótica, é uma função expectável e procurada pelos hóspedes. Em segundo lugar, cabe aos rececionistas o papel de divulgação da animação turística seja de forma proativa ou na resposta às solicitações dos hóspedes. Esta circunstância sobrevaloriza a importância da interação rececionista-hóspede para efeitos do processo de satisfação dos turistas no âmbito do serviço de alojamento. Finalmente, em terceiro lugar, as informações e divulgações realizadas pelos alojamentos turísticos, na figura dos seus rececionistas, têm um potencial de influência das atividades realizadas pelos hóspedes no destino turístico e, por consequência, na sua experiência global.

A conceção e exploração do estudo de caso, permitiu confirmar os indícios trazidos do marco teórico e fundamentá-los de forma concreta e aprofundada. Considerando as quatro questões fundamentais do estudo, encontraram-se respostas precisas e suportadas estatisticamente. Ao nível da perceção dos rececionistas sobre a problemática em estudo, constata-se que uma grande maioria está consciencializada para a importância do papel de divulgação de atividades de animação por parte dos estabelecimentos de alojamento. Ao mesmo tempo, pelas suas ações, também comprovam que coloca em prática as suas perceções ao sugerir ativamente locais e eventos aos hóspedes. Do lado da procura regista-se que a maioria dos hóspedes procura junto dos rececionistas informações sobre restauração local e atrativos a visitar junto dos rececionistas. Significa isto que não obstante a quantidade de informação sobre estes elementos em diversas plataformas de Internet o fator de conhecimento humano e experiência local do rececionista é, de facto, muito valorizado. A este nível, a interação que surge com os rececionistas, resulta numa evidente satisfação por parte dos hóspedes em três domínios: i) pela utilidade das informações, ii) pelo contributo para a experiência global no destino turístico e iii) pela qualidade dos conhecimentos 
transmitidos pelos rececionistas. Uma última resposta confirmada diz respeito à capacidade de influência positiva dos rececionistas para orientar os atrativos a visitar pelos hóspedes - cerca de $2 / 3$ das visitas estão associadas a sugestões prévias - e ao potencial comercial deste profissionais pois constatou-se que mais de $70 \%$ das compras de atividades de animação ocorreram após sugestões na receção dos alojamentos turísticos.

Em forma de resumo, a grande conclusão desta investigação reside na centralidade da ação humana de acolhimento e atendimento dos turistas no contexto do alojamento turístico como elemento capaz de influenciar a experiência no destino e ser fator importante para a satisfação do visitante. Este estudo contribui para colmatar lacunas visíveis pela reduzida literatura e estudo sobre as relações dos alojamentos turísticos e a animação dos destinos, bem como pela relevância do papel dos rececionistas. Espera-se, por isso, que sirva de base para um maior incentivo à participação da componente humana na receção de hóspedes, não descurando nunca o valor das tecnologias de comunicação e informação, e para sublinhar as vantagens práticas que os estabelecimentos de alojamento encontram na sua ligação com as atividades de animação pois para além de se poder constituir como uma fonte de receitas adicionais, representa a inclusão de serviços complementares e de uma maior importância do alojamento na experiência turística.

\section{Bibliografia}

Abreu, D. de. 2006. Análise de Dados II. Em Estudos para o planeamento regional e urbano $n^{\circ} 69$. Lisboa: Centro Estudos Geográficos Universidade de Lisboa.

Almeida, P., \& Araújo, S. 2012. Introdução à Gestão de Animação Turística. Lisboa: Lidel.

Barnes, S. J., Mattsson, J., Sørensen, F., \& Jensen, J. F. 2020. Measuring employee-tourist encounter experience value: A big data analytics approach. Expert Systems With Applications, 154, 113450.

Cândido, Í., \& Viera, E. V. de. 2003. Gestão de hotéis: técnicas, operações e serviços. Caxias do Sul: Educs.

Chen, W.-J. 2016. The model of service-oriented organizational citizenship behavior among international tourist hotels. Journal of Hospitality and Tourism Management, 29, 24-32.

Costa, J., Rita, P., \& Águas, P. 2004. Tendências Internacionais em Turismo. Lisboa: Lidel.

Costa, R. 2012. Introdução à Gestão Hoteleira (4. ${ }^{a}$ Edição). Lisboa: Lidel.

Cunha, L. 2013. Economia e política do turismo. (Lidel, Ed.) (3. ${ }^{\text {a). Lisboa. }}$

Davidoff, D. M. 1994. Contact: Customer Service in the Hospitality and Tourism Industry. New Jersey: Prentice Hall.

Instituto Nacional de Estatístca I.P. 2018a. Anuário Estatístico da Região Alentejo 2017. Lisboa: Instituto Nacional de Estatística I.P.

Instituto Nacional de Estatístca I.P. 2018b. Anuário Estatístico da Região Centro 2017. Lisboa: Instituto Nacional de Estatística I.P.

Instituto Nacional de Estatístca I.P. 2018c. Anuário Estatístico da Região Norte 2017. Lisboa: Instituto Nacional de Estatística I.P.

King, C. A. 1995. Viewpoint - What is hospitality? International Journal of Hospitality Management, 14(3/4), 219-234.

Marques, J. A. 2007. Manual de Hotelaria: políticas e procedimentos. Porto: Livraria Civilização Editora.

Martinelli, J. C. 2004. Fundamentos multidisciplinares do turismo: hotelaria. Em M. G. dos R. Ansarah

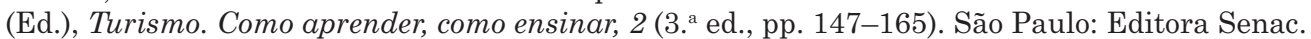

Mody, M., Suess, C., \& Lehto, X. 2019. Going back to its roots: Can hospitableness provide hotels competitive advantage over the sharing economy? International Journal of Hospitality Management, $76,286-298$.

Moita, P. 2017. e-Business em Turismo. Em F. Silva \& J. Umbelino (Eds.), Planeamento e Desenvolvimento Turístico (pp. 159-171). Lisboa: Lidel.

Moufakkir, O., \& Alnajem, M. N. 2017. Hostel front desk employees' perception of customers: a comparative analysis based on cultural background. International Journal of Culture, Tourism and Hospitality Research, 11(3), 355-371.

Oh, H., Jeong, M., \& Baloglu, S. 2013. Tourists' adoption of self-service technologies at resort hotels. Journal of Business Research, 66, 692-699.

Pestana, M. H., \& Gageiro, J. N. 2014. Análise de dados para Ciências Sociais - A complementaridade do SPSS (6. ${ }^{a}$. Lisboa: Edições Sílabo.

Pina, L. W., \& Ribeiro, O. C. F. 2007. Lazer e recreação na hotelaria. São Paulo: Editora Senac. 
Puertas, X. 2007. Gestión del ocio en el ámbito turístico. Madrid: Editorial Sintesis.

Romão, J. 2013. Turismo e Lugar. Lisboa: Escolar Editora.

Shoval, N., McKercher, B., Ng, E., \& Birenboim, A. 2011. Hotel location and tourist activity in cities. Annals of Tourism Research, 38(4), 1594-1612.

Teng, C.-C., \& Barrows, C. W. 2009. Service orientation: antecedents, outcomes, and implications for hospitality research and practice. The Service Industries Journal, 29(10), 1413-1435. 